\title{
NOTA
}

\section{ESTIMATIVA DA ACIDEZ POTENCIAL PELO MÉTODO DO PH SMP EM SOLOS DO ESTADO DO RIO DE J ANEIRO(1)}

\author{
M. G. PEREIRA ${ }^{(2)}$, G. S. VALLADARE ${ }^{(3)}$, J . M. P. F. SOUZA ${ }^{(3)}$, \\ D. V. PÉREZ ${ }^{(4)} \&$ L. H. C. DOS ANJ OS ${ }^{(2)}$
}

\begin{abstract}
RESUMO
A extração da acidez potencial com acetato de cálcio $0,5 \mathrm{~mol} \mathrm{~L}-1$ é um método amplamente utilizado nos laboratórios de análises de solo no Brasi l. Neste trabal ho, foram analisadas cento e duas amostras de solos do Estado do Rio de J aneiro, em 1996, visando obter a curva de calibração entre a acidez potencial e o pH de equilíbrio da suspensão de solo com solução-tampão (pH SMP). Os resultados demonstraram que a acidez potencial pode ser esti mada por meio da curva de regressão da soluçãotampão SMP $\left(R^{2}=0,90^{* *}\right)$. Também foi observada correlação significativa entre o pH de equilíbrio da suspensão de acetato de cálcio 0,5 mol L-1 e o pH SMP.
\end{abstract}

Termos de indexação: pH do solo, acidez extraível, análise química de solos.

\section{SUMMARY: ESTIMATION OF POTENTIAL ACIDITY BY PH SMP METHOD IN SOILS FROM RIO DE J ANEIRO STATE, BRAZIL}

The potential extractable acidity method by $\mathrm{Ca}(\mathrm{OAc})_{2} 0.5 \mathrm{~mol} \mathrm{~L}^{-1}$ is widely used in Brazilian soil analysis laboratories. To definethecalibrati on curvebetween potential extractable acidity and buffered pH SMP, 102 samples of soils from Rio de J aneiro State, Brazil, were analyzed in 1996. The data showed that potential acidity can be estimated by pH SMP buffer suspension $\left(\mathrm{R}^{2}=0.90^{* *}\right)$ and that the $\mathrm{pH}$ of $\mathrm{Ca}(\mathrm{OAC})_{2} 0.5 \mathrm{~mol} \mathrm{L^{-1 }}$ suspensi on was significantly correlated with the pH SMP.

Index terms: soil pH, extractableacidity, chemical soil analysis.

\footnotetext{
(1) Recebido para publicação em fevereiro de 1997 e aprovado em dezembro de 1997.

(2) Professor do Departamento de Solos, Universidade Federal Rural do Rio de J aneiro. CEP 23890-000 Seropédica (RJ ).

(3) Aluno do curso de Engenharia Agronômica, UFRRJ. CEP 23890-000 Seropédica (RJ). Bolsista do CNPq - PIBIC.

(4) Pesquisador da EMBRAPA - Centro Nacional de Pesquisa de Solos. Rua J ardim Botânico, 1.024, CEP 22460-000 Rio de J aneiro (RJ ).
} 


\section{INTRODUÇÃO}

A determinação da acidez potencial $(\mathrm{H}+\mathrm{Al})$ pela utilização da solução de acetato de cálcio 0,5 mol L-1 a $\mathrm{pH}$ 7,0 é um método amplamente utilizado nos laboratórios de análises de solo em todo Brasil. Porém, esse método apresenta algumas limitações, tal como subestimar os valores de $\mathrm{H}+\mathrm{Al}$ nos solos que apresentam pH acima de 6,0, em razão do tamponamento deficiente da solução de acetato de cál cio para valores de pH na faixa de 6,5 a 7,0 (Raij, 1991). Além disto, oindicador utilizado apresenta difícil visualização do seu ponto de viragem, o que se deve, em parte, às impurezas dos reagentes analíticos utilizados.

Em outros países, a solução-tampão, denominada deSMP, compõe o método mais utilizado para anál ise da acidez, em virtude de sua simplicidade e eficiência no controle do $\mathrm{pH}$, como mostram os trabalhos de Shoemaker et al. (1961), Mc Lean et al. (1966) eTran \& Lierop (1982) para uma ampla diversidade de sol os. No Brasil, os resultados obtidos também confirmam essa eficiência (Freitas et al., 1968; Kaminski, 1974; Souza et al., 1980).

Inicialmente, a solução-tampão SMP foi desenvolvida para ser utilizada em um método rápido de determinação de calagem, proposto por Shoemaker et al. (1961). Entretanto, pela sua simplicidade analítica, o método podetambém ser empregado para avaliar a acidez potencial do solo.

Raij et al. (1979) observaram estreita correlação entre os val ores do $\mathrm{pH}$ de equilíbrio de suspensões de solo e da sol ução-tampão SMP com os teores de H +Al determinados pela extração com acetato de cálcio, sugerindo a possibilidade de se determinar a acidez potencial por meio da medida do $\mathrm{pH}$ de equilíbrio da solução SMP com solo. Quaggio (1983) verificou que, em solos com altos teores de alumínio extraível, pela solução-tampão SMP obtêm-se valores de $\mathrm{H}+\mathrm{Al}$ superiores aos da extração com acetato de cálcio, de acordo com a proposta original do método SMP, que foi desenvolvido para sol os ricos em alumínio trocável.

Este trabalho teve como objetivo definir a curva de regressão e o coeficiente de correlação entre os valores de $\mathrm{pH}$ SMP e H $+\mathrm{Al}$, além de correlacionar o valor do $\mathrm{pH}$ da suspensão de acetato de cál cio com os valores de pH SMP, obtidos em amostras de horizontes superficiais de sol os do Estado do Rio de J aneiro.

\section{MATERIAL E MÉTODOS}

No primeiro semestre de 1996, foram analisadas cento e duas amostras de horizontes superficiais de solos do Estado do Rio de J aneiro, provenientes da coleção de solos da EMBRAPA/CNPS e do Departamento de Solos da UFRRJ .

A acidez potencial $(\mathrm{H}+\mathrm{Al})$ foi extraída com acetato de cálcio a 0,5 mol L-1 pH 7,0 e determinada por titulação com $\mathrm{NaOH}$ 0,025 mol L-1. A sol ução extratora de acetato de cálcio teve o seu pH ajustado para 7,0 com ácido acético. Em um erlenmeyer de $125 \mathrm{~mL}$, adicionaram-se $5 \mathrm{~cm}^{3}$ de terra fina seca ao ar (TFSA) e $75 \mathrm{~mL}$ de solução extratora, agitando-se por $15 \mathrm{~min}$ e deixando-se em repouso por uma noite, sendo também preparada uma prova em branco. Após esse período, foram retirados $25 \mathrm{~mL}$ do sobrenadante, e procedeu-se à titulação com $\mathrm{NaOH} 0,025 \mathrm{~mol} \mathrm{~L}^{-1} \mathrm{em}$ presença de três gotas defenolftaléna alcoólica 3 dag L-1. O cál culo da acidez potencial foi feito, subtraindo-se do volumegastona titulação da amostra ovol ume gasto na titulação da prova em branco, sendo a unidade usada $\mathrm{mmol}_{\mathrm{C}} \mathrm{dm}^{-3}$. Além dessa determinação, efetou-se a leitura do $\mathrm{pH}$ da solução sobrenadante.

O pH SMP foi determinado segundo Raij \& Quaggio (1983). Foi preparada a seguinte sol ução: em um balão de $1 \mathrm{~L}$, adicionaram-se $3,6 \mathrm{~g}$ de $p$-nitrofenol dissolvidos em $100 \mathrm{~mL}$ de água destilada e com aquecimento, $6,0 \mathrm{~g}$ de cromato de potássio $\left(\mathrm{K}_{2} \mathrm{CrO}_{4}\right)$ e $106,2 \mathrm{~g}$ de cl oreto de cál cio $\left(\mathrm{CaCl}_{2} \cdot 2 \mathrm{H}_{2} \mathrm{O}\right)$, el evando-se o volume para, aproximadamente, $500 \mathrm{~mL}$ com água destilada. Agitou-se a mistura por $15 \mathrm{~min}$, e adicionados, em seguida 4,0 g de acetato de cál cio (Ca $\left.\left(\mathrm{CH}_{3} \mathrm{COO}\right)_{2} \cdot \mathrm{H}_{2} \mathrm{O}\right)$ previamente dissolvidos em $300 \mathrm{~mL}$ de água destilada. A solução foi agitada por mais 10 min e, após a adição de $5 \mathrm{~mL}$ de trietanolamina, foi novamente agitada até completa homogeneização. Ajustou-se opH para 7,5 e completou-se o vol ume com água destilada.

Para analisar o pH SMP nas amostras de terra, foram adicionadas $10 \mathrm{~cm}^{3}$ deTFSA, em frasco plástico de $50 \mathrm{~mL}, 25 \mathrm{~mL}$ de solução de $\mathrm{CaCl}_{2}$ 0,01 mol L-1 e $5 \mathrm{~mL}$ da solução-tampãoSMP, agitando-se por $15 \mathrm{~min}$. a 220 rpm. A pós repouso por uma hora, procedeu-seà leitura do pH de equilíbrio da suspensão de sol o com a solução-tampão.

\section{RESULTADOS E DISCUSSÃO}

Os valores de $\mathrm{pH}$ SMP obtidos pela leitura em potenciômetro variaram de 3,8 a 7,4, e os da acidez potencial $(\mathrm{H}+\mathrm{Al})$, determinados por titulometria, de 7,0 a $539,0 \mathrm{mmo}_{\mathrm{c}} \mathrm{dm}^{-3}$. A depressão do $\mathrm{pH}$ da soluçãotampão SMP e a concentração de $\mathrm{H}+\mathrm{Al}$ extraída do solo com acetato de cálcio 0,5 mol L-1 correlacionaramse inversamente, isto é, o aumento da concentração de $\mathrm{H}+\mathrm{Al}$ relacionou-se com a diminuição do pH SMP (Figura 1).A correlação curvilinear simples obtida entre as características analisadas foi negativa $(R=-0,95 * *)$, ea curva de regressão estimada adequou-se ao model o exponencial (Figura 1), sendo explicada pela equação In $Y=10,05-1,02 X\left(R^{2}=0,090^{* *}\right)$. O quadro 1 , construído a partir dessa equação, permitea estimativa dos valores de $\mathrm{H}+\mathrm{Al}$ a partir dos resultados de $\mathrm{pH}$ SM P. O resultado encontrado apresenta tendência similar ao obtido por Quaggio (1983) e Sousa et al. (1989), estudando, respec-tivamente, sol os do Estado de São Paulo e do cerrado. Entretanto, utilizando qual quer uma das equações de regressão obtidas por esses autores, subestimar-se-ia o resultado de acidez potencial para as amostras analisadas neste estudo, sendo o erro maior quando utilizada a equação estabelecida por Sousa et al. (1989). 
Quadro 1. Conversão devalores de pH SMP para acidez potencial $(\mathrm{H}+\mathrm{Al})$, expressa em $\mathrm{mmol}_{\mathrm{c}} \mathrm{dm}^{-3}$, para solos do Estado do Río de J aneiro

\begin{tabular}{cccc}
\hline pH SMP & H + Al & pH SMP & H + Al \\
\hline 3,5 & 650,1 & 5,8 & 62,3 \\
3,6 & 587,1 & 5,9 & 56,2 \\
3,7 & 530,2 & 6,0 & 50,8 \\
3,8 & 478,8 & 6,1 & 45,9 \\
3,9 & 432,3 & 6,2 & 41,4 \\
4,0 & 390,4 & 6,3 & 37,4 \\
4,1 & 352,6 & 6,4 & 33,8 \\
4,2 & 318,4 & 6,5 & 30,5 \\
4,3 & 287,5 & 6,6 & 27,5 \\
4,4 & 259,6 & 6,7 & 24,9 \\
4,5 & 234,5 & 6,8 & 22,5 \\
4,6 & 211,7 & 6,9 & 20,3 \\
4,7 & 191,2 & 7,0 & 18,3 \\
4,8 & 172,7 & 7,1 & 16,5 \\
4,9 & 155,9 & 7,2 & 14,9 \\
5,0 & 140,8 & 7,3 & 13,5 \\
5,1 & 127,1 & 7,4 & 12,2 \\
5,2 & 114,8 & 7,5 & 11,0 \\
5,3 & 103,7 & 7,6 & 9,9 \\
5,4 & 93,6 & 7,7 & 9,0 \\
5,5 & 84,6 & 7,8 & 8,1 \\
5,6 & 76,4 & 7,9 & 7,3 \\
5,7 & 68,9 & 8,0 & 6,6 \\
\hline
\end{tabular}

Pela análise da correlação curvilinear simples entrea acidez potencial eo $\mathrm{pH}$ da suspensão de acetato de cálcio $0,5 \mathrm{~mol} \mathrm{~L}^{-1}\left(\mathrm{R}=0,82^{* *}\right)$, pode-se inferir que os menores valores de $\mathrm{pH}$ em acetato de cálcio correspondem aos maiores níveis de acidez potencial nesses sol os, o que confirma a alta relação entre tais características (Figura 3). A figura 2 mostra que o aumento dos valores de $\mathrm{pH}$ da solução de acetato de cálcio é diretamente proporcional aos valores de $\mathrm{pH}$ da solução SMP.

O quadro 2, construído a partir da equação obtida entre a acidez potencial e os valores do $\mathrm{pH}$ da suspensão em acetato de cál cio (F igura 3), possibilita estimar os valores de $\mathrm{H}+\mathrm{Al}$ a partir dos valores do pH da suspensão de acetato de cál cio.

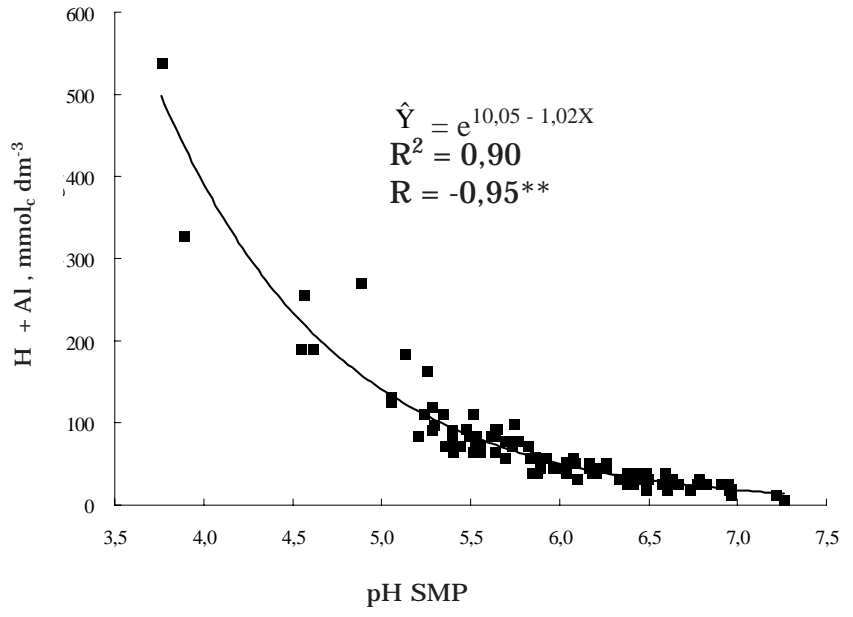

Figura 1. Relação entre a acidez potencial $(\mathbf{H}+\mathrm{Al})$ e o pH SMP.

Quadro 2.Conversão do pH da suspensão de acetato de cálcio para acidez potencial $(\mathrm{H}+\mathrm{Al})$, expressa em $\mathbf{m m o l}_{\mathrm{c}} \mathrm{dm}^{-3}$, para solos do E stado do R io deJ aneiro

\begin{tabular}{cccc}
\hline $\begin{array}{c}\text { pH da suspensão } \\
\text { de acetato de cálcio }\end{array}$ & H + Al & $\begin{array}{c}\text { pH da suspensão } \\
\text { de acetato de cálcio }\end{array}$ & H + Al \\
\hline 6,3 & 302,5 & 7,2 & 6,2 \\
6,4 & 196,4 & 7,3 & 4,0 \\
6,5 & 127,5 & 7,4 & 2,6 \\
6,6 & 82,8 & 7,5 & 1,7 \\
6,7 & 53,7 & 7,6 & 1,1 \\
6,8 & 34,9 & 7,7 & 0,7 \\
6,9 & 22,6 & 7,8 & 0,5 \\
7,0 & 14,7 & 7,9 & 0,3 \\
7,1 & 9,5 & 8,0 & 0,2 \\
\hline
\end{tabular}

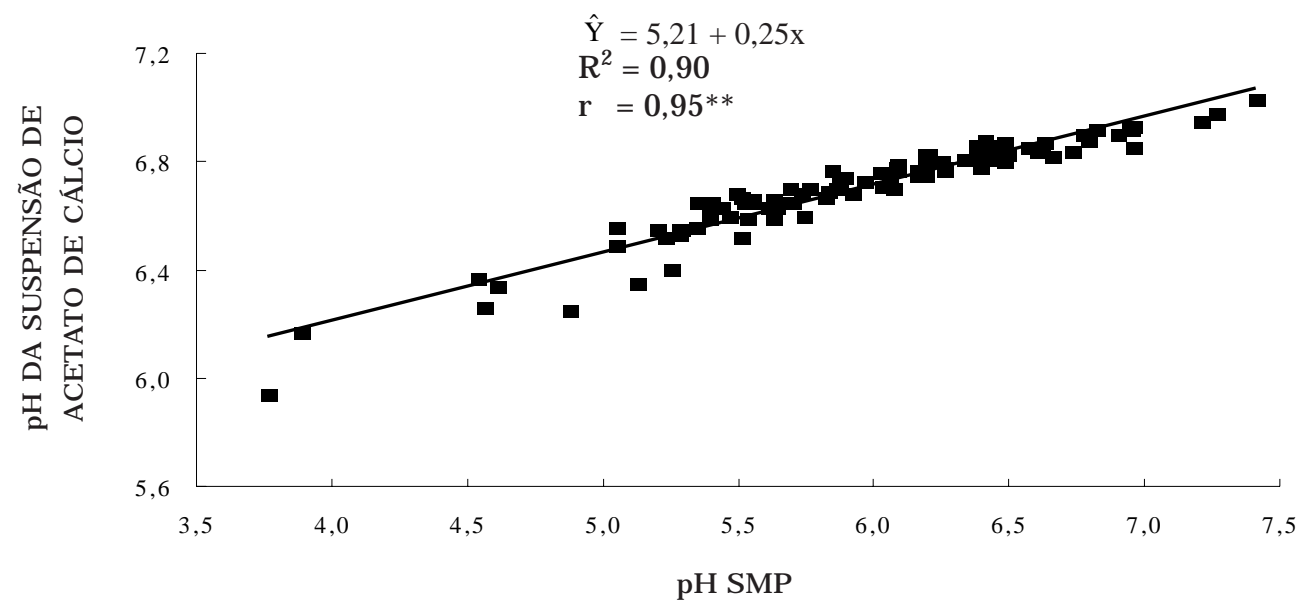

Figura 2. Relação entre o pH da suspensão de acetato de cálcio e o pH SMP. 


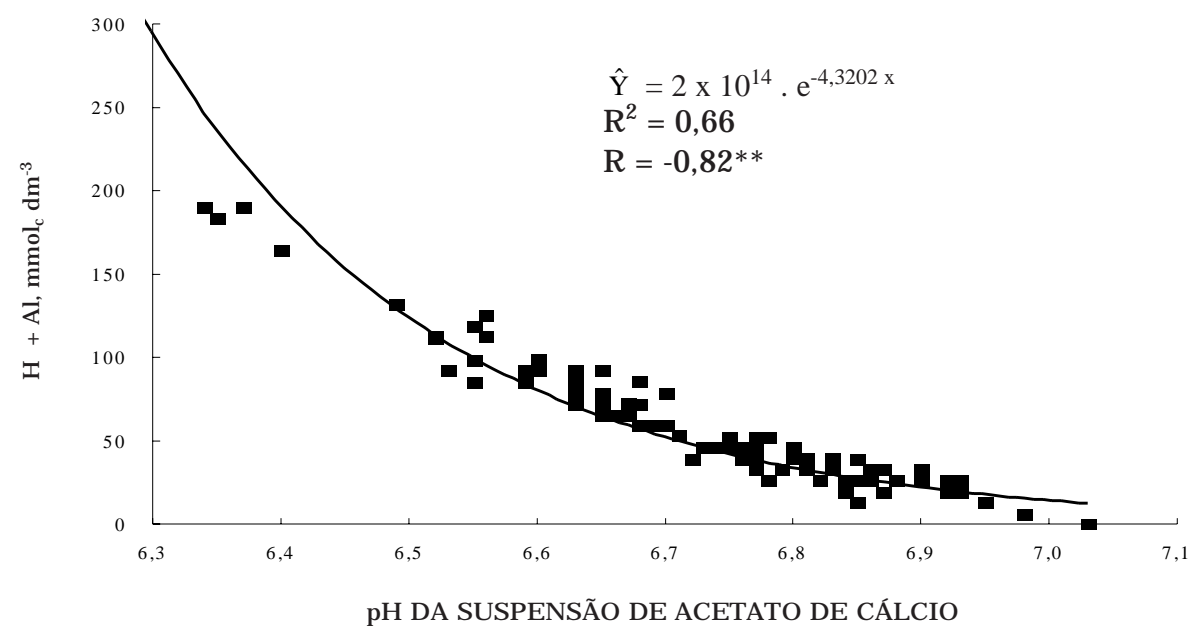

Figura 3. Relação entre o pH da suspensão de acetato de cálcio e a acidez potencial (H + Al).

\section{CONCLUSÕES}

1. Foi verificada a existência de correlação significativa entre os valores da acidez potencial e do pH na solução SMP, bem como do pH da suspensão de acetato de cál cio $0,5 \mathrm{~mol} \mathrm{L-1}$ com os teores de acidez potencial e pH SMP.

2. A acidez potencial podeser determinada por meio do pH no tampão SMP nos solos do Estado do Rio de J aneiro.

\section{LITERATURA CITADA}

FREITAS, L.M.M.; PRATT, P.F. \& VETTORI, L. Testes rápidos para estimar a necessidade de cal cário em al guns solos do estado de São Paulo. Pesq. Agrop. Bras., 3:159-164, 1968.

KAMINSKI, J . Fatores da acidez enecessidade de cal cário em sol os do Rio Grande do Sul. Porto Alegre, Universidade Federal do Rio Grande do Sul, 1974. 96p. (Tese de Mestrado)

MCLEAN, E.O.; DUNFORD, S.W. \& CORONEL, F.A. Comparasion of several methods of determining lime requirement of soils. Proc. Soil Sci. Soc. Am., 3:26-30, 1966.
QUAGGIO, J.A. Métodos de laboratório para calagem em solo. In: RAIJ, B. van; BATAGLIA, O.C. \& SILVA, N.M. Coord. Acidez e calagem no Brasil. In: REUNIÃO BRASILEIRA DE FERTILIDADE DO SOLO, 15., Campinas, 1983. Anais. Campinas, Sociedade Brasileira de Ciência do Solo, 1983. p.3348.

RAIJ, B. van.; CANTARELLA, H. \& ZULLO, M.A.T. O método tampão SMP para determinação da necessidade de calagem de solos do Estado de São Paulo. Bragantia, 38:57-69, 1979.

RAIJ , B. van. \& QUAGGIO, J.A. Métodos de análise de solo para fins defertilidade. Campinas, InstitutoAgronômico, 1983. 31p. (Boletim Técnico, 81)

RAIJ, B. van. Fertilidade do solo e adubação. Piracicaba, Ceres Potafos, 1991. 343p.

SHOEMAKER, H.E.; MCLEAN, E.O.\& PRATT, P.F. Buffer methods for determining lime requirement of soils with appreciable amounts of extractable aluminum. Proc. Soil Sci. Soc. Am., 25:274-277, 1961.

SOUSA, D.M.G.; MIRANDA, L.N.; LOBATO, E. \& KLIEMAN, H.J Avaliação de métodos para determinar de calcário em solos do cerrado de Goiás e do Distrito Federal. R. Bras. Ci. Solo, 4:144-148, 1980.

SOUSA, D.M.G.; MIRANDA, L.N.; LOBATO, E. \& CASTRO, L.H.R. Métodos para determinar de calagem em sol os de cerrado. $R$. Bras. Ci. Solo, 13:193-198, 1989.

TRAN, T.S. \& LIEROP, W. van. Lime requirement determination for attaining $\mathrm{pH} 5,5$ and 6,0 of coarsed-textured soil using buffer pH methods. Soil Sci. Soc. Am. J ., 46:1008-1014, 1982. 